\title{
Retraction Note: Tropical cyclone and business English cross-cultural communication based on temporal big data
}

\author{
Xiaoxu Wei ${ }^{1} \cdot$ Liqun Liu $^{1}$
}

Published online: 15 November 2021

C) Saudi Society for Geosciences 2021

Retraction Note to: Arabian Journal of Geosciences (2021) 14: 1734 https://doi.org/10.1007/s12517-021-07894-7

The Editor-in-Chief and the Publisher have retracted this article because the content of this article is nonsensical. The peer review process was not carried out in accordance with the Publisher's peer review policy. The authors have not responded to correspondence regarding this retraction.

Xiaoxu Wei

weixiaosusq@163.com

1 Suqian University, Suqian 223800, Jiangsu, China 